\title{
Failure Analysis of Slope Bolting and Shotcrete Structure under Ultimate
}

\section{Condition}

\author{
Quanchao B| ${ }^{1-2, a)}$, Mingxiu ZHANG ${ }^{1, b)}$,Xuelei WANG ${ }^{1, \mathrm{c})}$,Qiang RAO ${ }^{1, \mathrm{~d})}$ \\ ${ }^{1}$ Hebei Institute of Architectural Engineering, Zhangjiakou City, Hebei Province, 075000,China \\ ${ }^{2}$ Hebei Key Laboratory for Diagnosis, Reconstruction and Anti-disaster of Civil Engineering, China \\ a) hbjzdxbqc@sina.com \\ b)Corresponding author: 726588995@qq.com
}

\begin{abstract}
Key words:Spray anchor support;Bearing the limit;Debonding phenomenon;Thickness of spray layer
\end{abstract}

\begin{abstract}
In the frozen area, the freeze-thaw cycle may lead to the separation of the concrete spray and the slope in the spray anchor structure, resulting in failure of the spray anchor structure.In this paper, the gravity of the spray layer itself is decomposed by the force equivalence principle and the Saint-Venant principle,and two kinds of damage assumptions are put forward and analyzed and calculated.The results show that the thickness of the spray layer should not be too large under the limit condition of the coating layer and the slope body completely deodorized. Otherwise, the bolt will be broken; When taking the shot anchor support measures, should take into account the local crushing of concrete and steel shear fracture two cases.
\end{abstract}

\section{INTRODUCTION}

Spray anchor support is one of the most common slope control measures, is used to prevent loosening and separation of rock and soil, to improve the stability of the slope is important.

Spray anchor support is widely used in engineering practice as a common form for slope reinforcement. With the migration of water and its conversion between the three phases, there will be concrete spray layer and slope of the phenomenon of debonding, and lead to damage to the support structure. In order to prevent the phenomenon of peeling off the concrete spray and the slope, the limit state analysis of the spray anchor structure is very important for the safety of the actual engineering.

\section{ANALYSIS OF BOLT FORCE}

Taking a soil slope as an example,Assuming its slope is $\alpha$,anchorage angle is $\beta$,bolt spacing is $m$, the diameter of the bolt is $d$, the thickness of the spray layer is $n$, the bulk density of shotcrete is $\rho$, which the range is $2200 \sim 2300 \mathrm{~kg} / \mathrm{m}^{3}$.

Assuming that the concrete spray and the slab are deflated, but the anchoring system is not damaged, the anchor is subjected to all the gravity from the spray itself. As the anchor is evenly arranged, so a single anchor as a unit body, attached to the concrete in accordance with the area evenly divided into consideration, analysis of force. As shown in Figure 1. 


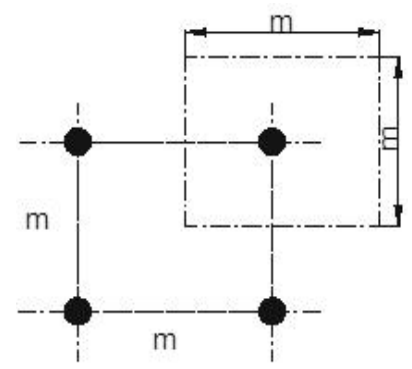

Figure 1. Bolt layout.

Simple analysis of the bolt:

The concrete gravity is decomposed into vertical force $F_{1}$ in the direction of the bolt and the force $F_{2}$ parallel to the direction of the bolt, as shown in Fig. As shown in picture 2.

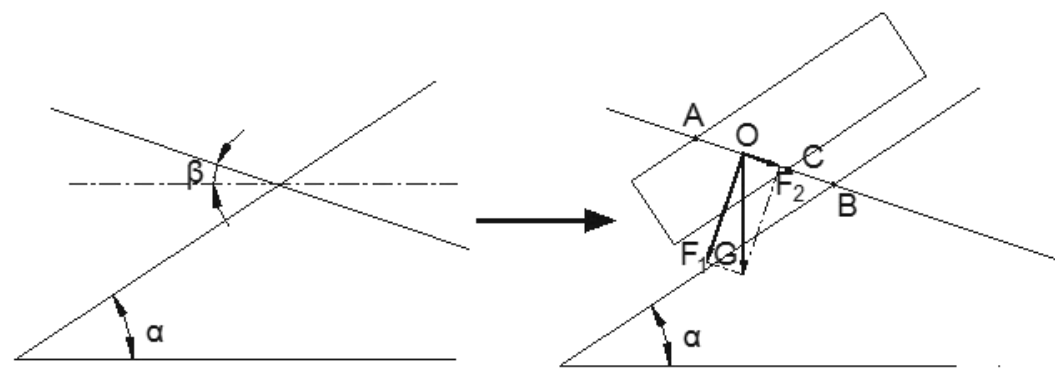

Figure 2.The self - weight decomposition of the spray layer.

Among them, the size of each force as follows:

$G=m^{2} \cdot n \cdot \rho \cdot g$

$F_{1}=G \cdot \sin (\alpha+\beta)$.

$F_{2}=G \cdot \cos (\alpha+\beta)$.

\section{DESTRUCTION HYPOTHESIS}

The following assumptions about the way of damage:

1) Concrete spray layer due to their own weight is too large, and the anchor contact with the upper part of the concrete crushing;

2) In the steel and concrete contact surface, reinforced shear fracture, spray layer fall collapse. 


\section{Theoretical Analysis and Calculation of Limit State Hypothesis}

\section{Concrete local crushing hypothesis}

The gravity of the concrete spray is all transferred to the anchor, which may cause local crushing of the concrete at the upper surface of the contact with the anchor. According to the Saint-Venant principle, if assumed to be established, it is only possible that the concrete with the concrete's contact surface is crushed.

The effective contact area of single steel bar and concrete spray layer is:

$$
S=n \cdot d / \sin (\alpha+\beta) \text {. }
$$

The gravity of concrete units:

$$
G=m^{2} \cdot n \cdot \rho \cdot g \text {. }
$$

The value of the shear force is:

$$
V=F_{1}=G \cdot \sin (\alpha+\beta) \text {. }
$$

Contact surface concrete compressive stress:

$$
\sigma=\frac{V}{S}=\frac{m^{2} n \rho g \cdot \sin (\alpha+\beta)}{n \cdot d / \sin (\alpha+\beta)}=\frac{m^{2} \rho g \cdot \sin ^{2}(\alpha+\beta)}{d} .
$$

It can be seen from the above formula, the contact surface concrete compressive stress and spray layer thickness has nothing to do, and with the slope angle, anchor angle and bolt spacing is proportional to the diameter of the bolt inversely proportional.The results are shown in Table 1.

Table 1. Calculation of concrete compression

\begin{tabular}{ccccc}
\hline $\begin{array}{c}\text { Slope angle } \\
\alpha[\circ]\end{array}$ & $\begin{array}{c}\text { Anchorage } \\
\text { angle } \beta[\circ]\end{array}$ & $\begin{array}{c}\text { Bolt spacing } \\
m[\mathrm{~m}]\end{array}$ & $\begin{array}{c}\text { Boltdiameter } \\
d[\mathrm{~mm}]\end{array}$ & $\begin{array}{c}\text { Whether the } \\
\text { concrete is } \\
\text { damaged }\end{array}$ \\
\hline 50 & 10 & 4 & 18 & No \\
50 & 10 & 5 & 18 & No \\
50 & 10 & 6 & 18 & No \\
65 & 0 & 5 & 18 & Yes \\
65 & 10 & 4 & 18 & No \\
65 & 10 & 5 & 18 & No \\
65 & 10 & 6 & 18 & Yes \\
80 & 0 & 5 & 18 & Yes \\
80 & 10 & 4 & 18 & No \\
80 & 10 & 5 & 18 & No \\
80 & 10 & 6 & 18 & Yes \\
\hline
\end{tabular}

From the table can be drawn:The effect of anchorage angle on the compression of concrete is small, and the angle between the slope and the bolt has a great influence on the compression of concrete. If the slope angle is slow, may be appropriate to increase the bolt spacing. 


\section{THEORETICAL CALCULATION}

In this paper, the shear analysis of steel bars is carried out on the assumption that the steel joints are subjected to shear fracture at the interface with concrete ,according to the shear formula $\tau=V / A$ to determine the maximum contact surface of the shear point $C$ where the steel section.

Reinforcement is subjected to shear:

$$
\tau=\frac{V}{A}=\frac{F_{4}}{A}=\frac{m^{2} n \rho g \cdot \sin (\alpha+\beta)}{A} .
$$

From the formula (4) available, in the ultimate resistance of the steel in the state, the maximum thickness of the spray layer can be expressed as

$$
n_{\text {max }}=\frac{\tau_{\max } \cdot A}{m^{2} \rho g \cdot \sin (\alpha+\beta)} .
$$

From the above formula, the shear force of the steel bar is proportional to the slope angle, the anchorage angle, the bolt spacing and the spray layer thickness, and is inversely proportional to the cross section area of the steel bar.The ultimate shear strength of Q235 steel bars is calculated and the results are shown in Table 2.

\begin{tabular}{|c|c|c|c|c|}
\hline $\begin{array}{c}\text { Slope angle } \\
\alpha[\circ]\end{array}$ & $\begin{array}{l}\text { Anchorage } \\
\text { angle } \beta[\circ]\end{array}$ & $\begin{array}{l}\text { Bolt spacing } \\
\qquad m[\mathrm{~m}]\end{array}$ & $\begin{array}{c}\text { Bolt } \\
\text { diameter } \\
d[\mathrm{~mm}]\end{array}$ & $\begin{array}{c}\text { Thickness of } \\
\text { spray layer } \\
n[\mathrm{~mm}]\end{array}$ \\
\hline 50 & 10 & 2 & 18 & 408 \\
\hline 50 & 10 & 3 & 18 & 181 \\
\hline 50 & 10 & 4 & 18 & 102 \\
\hline 50 & 0 & 4 & 18 & 115 \\
\hline 50 & 4 & 4 & 18 & 109 \\
\hline 50 & 8 & 4 & 18 & 104 \\
\hline 60 & 10 & 2 & 18 & 375 \\
\hline 60 & 10 & 3 & 18 & 166 \\
\hline 60 & 10 & 4 & 18 & 94 \\
\hline 60 & 0 & 4 & 18 & 102 \\
\hline 70 & 10 & 2 & 18 & 358 \\
\hline 70 & 10 & 3 & 18 & 159 \\
\hline 70 & 10 & 4 & 18 & 89 \\
\hline 70 & 0 & 4 & 18 & 94 \\
\hline 80 & 10 & 2 & 18 & 352 \\
\hline 80 & 10 & 3 & 18 & 157 \\
\hline 80 & 10 & 4 & 18 & 88 \\
\hline 80 & 0 & 4 & 18 & 89 \\
\hline 80 & 10 & 4 & 16 & 69 \\
\hline 60 & 10 & 4 & 18 & 94 \\
\hline 60 & 10 & 4 & 20 & 116 \\
\hline 60 & 10 & 4 & 22 & 140 \\
\hline 60 & 10 & 4 & 25 & 181 \\
\hline 60 & 10 & 4 & 28 & 227 \\
\hline 60 & 10 & 4 & 30 & 261 \\
\hline
\end{tabular}

Table 2. Spray layer thickness calculation results. 
From the table can be drawn:

1) Anchorage angle, bolt spacing, bolt diameter of a certain situation, with the slope angle increases, spray layer thickness of the extreme value gradually reduced, and the smaller trend is getting slower and slower .

2) Slope angle, bolt spacing and bolt diameter are constant, with the increasing angle of anchorage angle, the extreme value of spray layer thickness gradually smaller, almost uniform trend and the trend is stable but the impact is very small .

3) Slope angle, anchor angle, bolt diameter of a certain situation, with the bolt spacing gradually increased, spray layer thickness of the extreme decreases sharply and the trend is getting slower and slower .

4) Slope angle, anchorage angle, bolt spacing of a certain situation, with the increase in the diameter of the bar, spray layer thickness of the extreme value of the greater, and the growing trend is growing .

The anchoring angle has little effect on the compression of the concrete and the thickness of the sprayed layer, while the slope angle and the bolt spacing have a greater effect on both; If the bolt spacing is large, should be appropriate to increase the selection of steel bar diameter.

\section{IN CONCLUSION}

In this paper, the gravity of the spray layer is decomposed by the force equivalence principle. Combined with the Saint-Venant principle, two kinds of assumptions of local crushing and buckling of concrete are put forward and the stress analysis and theoretical calculation are carried out. In the assumption that the spray layer and the slope completely out of the limit state, the following conclusions:

1)The compressive stress of the concrete in the contact surface is independent of the thickness of the spray layer and is proportional to the slope angle, the anchorage angle and the anchor pitch, and is inversely proportional to the diameter of the bolt.

2)Reinforcement suffered from shear and slope, anchorage angle, bolt spacing, spray layer thickness is proportional to the cross section with the steel area is inversely proportional.

3)The anchoring angle has little effect on the compression of the concrete and the thickness of the sprayed layer, while the slope angle and the bolt spacing have a greater effect on both

4) When taking the shot anchor support measures, should take into account the local crushing of concrete and steel shear fracture two cases.

\section{ACKNOWLEDGMENTS}

Fund project:

1Hebei Provincial Science and Technology Department of the project (Numbering:15275416)

2Zhangjiakou City Department of Transport Project(Study on Mechanical Behavior and Disaster Prevention of Anchorage Structure of Cutting Slope under Freeze-thaw Cycling Numbering:16033)

3Hebei Institute of Architectural Engineering School level Graduate Innovation Fund(Numbering:XA201709)

\section{About the Author:}

1Quanchao BI(1981-), male, master, associate professor, research direction: geotechnical engineering and engineering structure research. Tel: 13833339040. E-mail: hbjzdxbqc@sina.com

2Mingxiu ZHANG(1992-), male, master in graduate school, research direction: bridge and tunnel engineering.Tel: 18222902623. E-mail:726588995@qq.com 


\section{REFERENCES}

[1]Weiyong Zhang: Elementary Analysis the Advantage of Anchor bolt-spray Support [J]. SUBGRADE ENGINEERING,2004,(4):60-62.

[2]Bi Quanchao,Wang Xuelei,Zhang Tao:The discussion on slope disaster and prevention measures under freeze-thaw cycles[J]. Shanxi Architecture,2016,42(33):66-67.

[3]Bi Quanchao,Wang Xuelei,Dong Jie:Stress Analysis of Slope Anchor Structure Under Reeze-thaw Cycles[J]. Science \& Technology Information, 2017,15(1):57-60.

[4]YANG Yu-chuan,YANG Xing-guo,XING Hui-ge,etal: An Analysis of the Stability of Shotcrete-bolt Supported Slope Based on the Principle of Pressure Transmission[J]. China Rural Water and Hydropower,2014,(11):101-104,108.

[5]Hu Juyi,Wen Haijia,Zhang Yongxing,etal: Retaining Structure with Bolting and Shotcreting for High Slope and the Forecast of Reliability[J]. Geotechnical Investigation \& Surveying,2004, (6).

[6]Zhan Wei. Application of Bolting and Shotcreting Technology in Slope Support[J].GuangDong Science \& Technology. 2012, (3). 